\title{
Los juegos recreativos como vía para la estimular la memoria en educandos con discapacidad intelectual
}

\author{
The recreational games as way to stimulate the memory in scholars with \\ intellectual disability
}
Dania Pérez López. ${ }^{1}$, Omar Alvarez García. ${ }^{2}$, Reymer Sánchez Alberich. ${ }^{3}$ \& Efraín Velasteguí López. ${ }^{4}$

\begin{abstract}
.
All the societies and especially in Cuba they recognize educational and formative value that has the recreational games as part of the development of the processes physique, psychological and cognitive of the scholars with intellectual disability. This it is conceived like an indispensable tool where the professor of Physical Education can work the necessities of his scholars like part of the correction y/o compensation, leaving essentially of his potentialities. With the result that the objective of the investigation is: to elaborate a program of recreational games that contributes to stimulate the memory in scholars with intellectual disability of the special school Camilo Cienfuegos. Methods of the theoretical, empiric and mathematical level were applied; those that allowed determined the theoretical and methodological historical, relating antecedents that sustain the study object, the revision of the clinical files, observations and interviews. In this study one could the characteristic psycho-pedagogical of the sample study object as well as to determine that the memory was the critical route in the psychic development of the same ones, for this one worked with an intentional sample of 18 scholars, to those that were applied a battery of recreational games in a period of time of 10 months. The results reached in the investigation demonstrate that the proposed recreational games contributed to the stimulation of the memory and other psychic processes of these scholars with

\footnotetext{
${ }^{1}$ Profesora de Educación Física. Escuela primaria Carlos Aztiazarain. Cuba dania970509@gmail.com

2 Universidad de Ciencias de la Cultura Física y el Deporte "Manuel Fajardo", Cuba. omar830119@gmail.com

${ }^{3}$ Universidad de la Habana, Facultad de Turismo, Cuba. decubarecrea@gmail.com

4 Universidad Técnica de Babahoyo, Facultad de Ciencia de la Educación Babahoyo, Ecuador. evelastegui@utb.edu.ec
} 
intellectual disability and they can constitute a tool for the professors of Physical Education and educational psychologists of this school.

Keywords: recreational games, memory, scholars and intellectual disability.

\section{Resumen.}

Todas las sociedades y en especial en Cuba reconocen el valor educativo y formativo que tiene los juegos recreativos como parte del desarrollo de los procesos físico, psicológico y cognoscitivo de los educandos con discapacidad intelectual. Este se concibe como una herramienta indispensable donde el profesor de Educación Física puede trabajar las necesidades de sus educandos como parte de la corrección y/o compensación, partiendo esencialmente de sus potencialidades. De ahí que el objetivo de la investigación sea: elaborar un programa de juegos recreativos que contribuya a estimular la memoria en educandos con discapacidad intelectual de la escuela especial "Camilo Cienfuegos". Se aplicaron métodos del nivel teórico, empírico y matemático, los que permitieron determinar los antecedentes históricos, referentes teóricos y metodológicos que sustentan el objeto de estudio, la revisión de los expedientes clínicos, observaciones y entrevistas. En este estudio se revelaron las características psicopedagógicas de la muestra objeto de estudio, así como determinar que la memoria era la ruta crítica en el desarrollo psíquico de los mismos, para esto se trabajó con una muestra intencional de 18 educandos, a los que se les aplicó una batería de juegos recreativos en un período de tiempo de 10 meses. Los resultados alcanzados en la investigación demuestran que los juegos recreativos propuestos contribuyeron a la estimulación de la memoria y otros procesos psíquicos de estos educandos con discapacidad intelectual, también pueden constituir una herramienta para profesores de Educación Física y psicopedagogos de esta escuela.

Palabras claves: juegos recreativos, memoria, educandos y discapacidad intelectual

\section{Introducción.}

El juego ocupa un lugar predominante en la vida del hombre desde sus orígenes y lo ha estado acompañando en su devenir histórico hasta la actualidad. En este trayecto, científicos, pedagogos y estudiosos del tema han mostrado sus posiciones con respecto al juego y su importancia desde las primeras etapas de la vida hasta la vejez. Otras miradas se le ha dado al juego desde la discapacidad intelectual donde se ha demostrado por la ciencia su valor físico, psicológico, educativo, profiláctico y terapéutico, lo que permite considerarlo como un medio indispensable para el desarrollo integral de la personalidad y más si se trata de educandos con discapacidad intelectual.

Por otra parte, Revilla (2016) infiere que el juego se constituye como una actividad genuina, espontánea, indispensable para que el escolar con retraso mental pueda desarrollarse, enriquecer sus percepciones, relacionarse y evocar sus necesidades, afectos y fantasías, disfrutar durante la exploración de su entorno en beneficio de la imaginación 
y comunicación, lograr nuevos aprendizajes, ser feliz, en la transformación del principal agente de aceptación y socialización dentro de un contexto sociocultural.

La memoria, como parte de los procesos cognoscitivos se considera un factor fundamental en el aprendizaje de los educandos con discapacidad intelectual, realizando las funciones psicológicas más complejas y difíciles. Estas son de vital importancia si se tiene en cuenta que la memoria es uno de los principales procesos que se ven afectados en la discapacidad intelectual, características esta que permite grabar informaciones, contenidos y experiencias para después reproducirla en el juego.

En este sentido, el profesor puede utilizar el juego recreativo como una herramienta necesaria para contribuir a la sensación de placer, gozo, independencia, seguridad confianza y la memoria. La estimulación y desarrollo de los procesos cognoscitivo, volitivo, afectivo y social, contribuye de manera positiva en los educandos, convirtiendo el juego en un método y medio de enseñanza.

Los educandos con discapacidad intelectual conciben los juegos recreativos como un refugio para descargar sus energías y agotamiento intelectual. Después del estudio de la literatura especializada que le ha dado tratamiento al proceso de los juegos recreativos en educandos con discapacidad intelectual, así como los resultados de la utilización de diferentes métodos de investigación científica entre los que se destacan múltiples observaciones realizadas a los diferentes espacios de deporte para todos, las clases de Educación Física y las actividades extracurriculares, se pudo determinar que a pesar de que existen antecedentes en la escuela especial "Camilo Cienfuegos" respecto a los juegos recreativos en educandos con discapacidad intelectual, se evidencia limitaciones en el trabajo con la memoria, al no contar con un programa de juegos recreativos que estimule y desarrolle este proceso. En consonancia con lo anteriormente mencionado, se tiene como problema científico ¿cómo contribuir a la estimulación de la memoria en los educandos con discapacidad intelectual de la escuela especial "Camilo Cienfuegos"?, siendo el objetivo de la misma: elaborar un programa de juegos recreativos que contribuya a estimular la memoria en educandos de 5to grado con discapacidad intelectual.

Numerosos estudios se han suscitado con respecto al juego desde los orígenes de la humanidad hasta la actualidad, aunque las definiciones abordadas no han logrado abarcar en sí la magnitud de este término, autores como Chateau (1966), Zapata (1968), Huisinga (1972), Bruner (1972), Niedospasova (1972), Medina (1987), Ruiz (1989), Orliek (1990), Carralero (2003) Watson, H. (2008), entre otros han definido indistintamente desde su perspectiva el juego como actividad motriz y generadora de alegrías y saberes. Estos autores le dan una mirada al juego desde la Educación Física, sin embargo, Pérez (2010), sin dejar de reconocer los autores anteriores y la importancia de sus aportes en el campo educacional, brinda una definición de juego concebido desde el tiempo libre o tiempo de la recreación, de ahí que defina el juego recreativo como:

(...) los juegos son un tipo de actividad especial espontánea u organizada que tiene gran importancia pedagógica, psicológica, socio-cultural y recreativa, ya 
que a través del mismo el niño puede desarrollar cualidades físicas; adquirir conocimientos; solidaridad; entre otros, a través del contacto social, al mismo tiempo produce placer (Pérez, 2010 p.128).

Por su parte, Costa et al. (2007), aseveran que las personas con discapacidad intelectual reciben, procesan y organizan la información con dificultad y lentitud. Por este motivo su posibilidad de respuesta también presenta limitaciones. La comprensión de las situaciones y problemas del entorno y la rapidez con la que responden a las demandas del mismo, se ven condicionadas por las dificultades para el procesamiento que presentan. En estas personas, todo aquello que posibilite la llegada de información exterior y la percepción de los estímulos sensoriales favorece su desarrollo cerebral. Por lo tanto, el empleo de apoyos apropiados puede mejorar sus capacidades funcionales. En este sentido, el juego puede moldear el funcionamiento cerebral e instaurar modificaciones sustanciales y duraderas que faciliten el aprendizaje. El juego, además de servir como herramienta de estimulación, también les ayuda a relacionarse con los demás, a mejorar su autoestima, a superarse, a transferir y generalizar los aprendizajes a otros entornos y, sobre todo, a divertirse.

Entre tanto, Revilla (2016) asegura que los juegos que se diseñen para la intervención psicopedagógica de educandos con discapacidad intelectual deben sustentarse en un conocimiento profundo de sus regularidades, sus necesidades y potencialidades, derivadas de un correcto diagnóstico y poner al descubierto la zona de desarrollo actual.

Lo cierto es que a medida en que los profesores y pedagogos seamos capaces de planificar, organizar, dirigir y controlar juegos que tributen a la estimulación cognitiva y en especial a la memoria vamos a estar incidiendo positivamente en su futuro desarrollo, teniendo en cuenta que el objetivo fundamental de la educación especial es prepararlos para su inserción social.

A continuación se asumen los beneficios del juego para la memoria según el sitio web: eresmama.com:

Mejora de la memoria visual: cuando los educandos hacen esta actividad se incrementa la memorización que se produce mediante la vista. La precesión se agudiza y las asociaciones visuales son internalizadas.

Motiva el pensamiento rápido: para los educandos estos juegos deben ser más eficientes y perceptivos, de esta forma, se acostumbran a generar respuestas intelectuales rápidas. En resumen, se trabaja el proceso de aprendizaje y resolución de problemas.

$\checkmark$ Se incrementa la concentración: este tipo de juego son una excelente forma de trabajar para los educandos. Los pequeños controlan el estímulo de la distracción porque les interesa completar el juego; la disciplina se interioriza hasta convertirse en un comportamiento normal. 
Memorizar es una actividad mental que se realiza en tres partes: grabación, almacenamiento y clasificación de la información. Cuando un educando hace de estos juegos su pasatiempo, simplemente realiza estos tres procesos mientras se divierte. El correcto desarrollo de todo el proceso de memorización conlleva la mejora del aprendizaje en su totalidad.

De igual forma pedagogos, médicos y especialistas han investigado sobre la discapacidad intelectual como son: Bell (1995), López (2000), Torres (2003), Guerra (2005), Gayle (2005), Garcés (2005), Guerra (2005), García (2006), Leyva y Barreda (2017), basados también en aportes de científicos foráneos dentro de los que figura Rubeinstein (1971), Bobath (1987), Vigotsky (1989), Verdugo (2010), Schalock (2010), Luckasson, (2010), entre otros.

Las investigadoras Leyva y Barreda (2017), perciben la discapacidad intelectual como:

(...) una condición relativamente estable del desarrollo que se caracteriza por limitaciones significativas y de diferentes grados en la actividad intelectual, en general, y en la adquisición de los aprendizajes conceptuales, prácticos y sociales revelados en los modos de actuación social, en particular; que requieren apoyos de diversa intensidad a lo largo de la vida. Se caracteriza por la variabilidad y diferencias de expresión en el funcionamiento (Leyva y Barreda, 2017, p.168).

Estas autoras aseveran que las características de los educandos con discapacidad intelectual no constituyen una categoría homogénea, pues presentan una evolución variable, en la cual lo individual se combina con lo común y varía con respecto a sí mismo y a los de su grupo. Esta discapacidad incidirá en todas las facetas del desarrollo, entre ellas: la independencia, la comunicación, el lenguaje, la interacción social, las relaciones personales, la motricidad, el aprendizaje y la memoria. Estas características están proyectadas atendiendo a la variabilidad en el desarrollo de cada educando, donde sus principales rasgos están en el desarrollo motor, desarrollo cognitivo- afectivo, desarrollo social, autonomía personal, desarrollo del lenguaje, la comunicación y la memoria.

Esta última se considera un proceso psíquico que nos permite la fijación, conservación y ulterior reproducción de la experiencia anterior, reaccionar a señales y situaciones que han actuado sobre nosotros, donde autores como Broadbent (1957), Crowder y Morton, (1969), James (1890), Tulving (1987), Klein (1994), Baddeley (1999), Fernández (2008), García (2011), Catalán (2016), De la Vega y Zambrano (2018), entre otros abordan tan complejo proceso y se asume de Catalán (2016) su definición de memoria y la conciben como:

(...) la memoria es una función cognitiva que nos permite almacenar información y recuerdos, y recuperarlos cuando sea necesario. Es decir, nos permite conservar la información que procesamos para poder recuperarla cuando sea necesario. Esta función cognitiva, es la que nos permite aprender, pues si no creásemos recuerdos de la información a la que accedemos, no podríamos adquirir conocimientos. (Catalán, 2016, pág.1) 
Es válido desatacar que aunque en la investigación solo se haya trabajado y se hace referencia a la memoria como componente fundamental, la misma está estrechamente ligada con otros procesos que en su conjunto forman los procesos cognitivos y dentro de los cuales se encuentran, la atención, el lenguaje, el razonamiento, el pensamiento, la imaginación, entre otros. Es decir que en la medida en que seamos capaces de estimular y desarrollar la memoria, se va a estar estimulando indistintamente estos procesos.

Entre tanto, autores como Cifuentes, Forero y Urrego (2015), quienes citan a (Flórez, 1999 McGuire y Chicoine, 2009) aseguran que las personas con discapacidad cognitiva poseen limitaciones y deficiencias en sus aptitudes intelectuales en este caso la memoria, específicamente la memoria a corto y largo plazo, y en memoria explicita o declarativa.

Continúan acotando que estos no conservan la memoria inmediata el tiempo suficiente para permitir las modificaciones que implica la memoria a largo plazo, lo que dificulta el pasar información de la memoria a corto plazo a la memoria a largo plazo generando deficiencia en la memorización de datos importantes del contexto. Es importante tener en cuenta que su memoria visual es mejor que su memoria auditiva y esta llega a ser una herramienta de trabajo para intervenir (pág. 25).

Al relacionar el juego con la memoria, la autora Bruner (2015) asevera que la memoria es concebida entonces como un proceso constructivo, un proceso creativo y no literal, de búsqueda de sentido. Y es en este punto donde podemos intentar ubicar el lugar del juego en la infancia, considera además que juego deja marcas, es decir huellas para toda la vida y que este permite el proceso de creación que dará lugar a los procesos de memoria en la infancia.

Esta misma autora un año más tarde, Bruner (2016) al referirse al juego destaca que el deseo de jugar y la formación psíquica del juego no surgen de manera espontánea, no son innatas, ni se heredan genéticamente y su advenimiento no depende de la dotación orgánico-biológica con la que se nace. Continúa además refiriéndose a que la construcción, constitución y desarrollo del escenario del juego o sea llegar a tener infancia, no está asegurado para todos los niños, proceso que si está garantizado en las escuelas especiales cubanas y hoy día se puede percibir a través del Currículo Institucional del Sistema Nacional de Educación.

\section{Metodología.}

Para llevar a cabo la investigación se utilizó el enfoque mixto donde se articulan los elementos cualitativos y cuantitativos, haciendo énfasis en la investigación descriptiva. Se emplearon también los métodos del nivel teórico como el histórico-lógico, el analíticosintético y el inductivo-deductivo los que permitieron fundamentar teóricamente la propuesta. De igual forma fueron utilizados métodos empíricos tales como: la observación, la entrevista, el análisis documental y los test psicológico, además se utilizaron también el estadístico matemático los que permitieron darle respuesta al problema de la investigación. 
El estudio el realizó en la escuela especial "Camilo Cienfuegos" del municipio Diez de Octubre, Cuba y cuenta con una matrícula de 180 educandos (62 hembras y 118 varones) en edades comprendidas entre 6 a 18 años de edad. Se partió de una población de 18 educandos diagnosticados con discapacidad intelectual y la muestra fue seleccionada de manera intencional haciéndose coincidente con la población (7 hembras y 11 varones), que representa el $100 \%$.

\section{Resultados.}

El estudio de los expedientes psicopedagógicos como parte de la revisión documental permitió conocer las características de los educandos del 5 to grado con los que se trabajó, siendo estas las siguientes:

- Presentan dificultades en el aprendizaje y trabajan con un III y IV nivel de ayuda, mientras que se constata disminución de la memoria (mediata e inmediata).

- Muestran signos de cansancio y fatiga antes las actividades ritmo de trabajos seguidos. Presentan además bajos niveles de concentración y se percibe rechazo antes la actividad docente

- Tienen inmadurez generalizada, dificultades en la pronunciación, vocabularios disminuidos, así como torpezas en la comprensión. Sus comportamientos por debajo de su edad cronológica, entre otras.

Por otra parte, la aplicación de métodos e instrumentos de la investigación científica como la observación, la entrevista y los test psicopedagógico (estos últimos aplicado por los investigadores bajo la supervisión de la psicopedagoga), arrojaron la necesidad de elaborar un programa de juegos recreativos para estimular la memoria de los educandos con discapacidad intelectual. A continuación se muestran la tabla 1 que refleja el estado actual de los educandos con respecto a la memoria según los 4 test psicológicos que se les aplicaron en el pre test:

Tabla 1

\begin{tabular}{lcccc}
\hline \multicolumn{1}{c}{ Test aplicadas } & \multicolumn{4}{c}{ Resultados } \\
& Alto & Medio & Bajo & Total \\
\hline Figuras incompletas & 4 & 2 & 9 & 18 \\
El rompecabezas & 16 & 1 & 1 & 18 \\
Memoria del ABC & 2 & 6 & 10 & 18 \\
Los objetos que recuerdo & 3 & 7 & 8 & 18 \\
\hline
\end{tabular}

Resultados de los test psicológicos aplicados en el pre test

\section{Programa de juegos recreativos}

Este programa de juegos recreativos está dirigido a los educandos con discapacidad intelectual de la escuela especial "Camilo Cienfuegos" del municipio Diez de Octubre; su objetivo general es estimular los procesos cognoscitivos (memoria) de los mismos y a su vez contribuir a la corrección y/o compensación. 


\section{Tipos de memoria que estimulan el programa de juegos recreativos propuesto:}

La memoria por imágenes: ya que en la mayoría de los juegos se utilizan imágenes (fotos, recortes y tarjetas con números, animales y figuras) para hacer más fácil y emotivo el trabajo con estos educando

$\checkmark$ Memoria lógica-verbal y memoria racional: estas se trabajan de conjunto estando, desde su aplicación de los juegos recreativos hasta la culminación del mismo ya que en todo momento los investigadores deben explicar y corregir las actividades e intentando buscar un resultado lógico, bajo el empleo de juegos comparativos, así como análisis para el completamiento de un conjunto de imágenes de historias

$\checkmark$ Memoria mecánica: esta se puede evidenciar durante los juegos en los que eran necesario una rápida respuesta, ejemplo en las cuentas matemáticas

Memoria mediata e inmediata: esta es en la que más se trabaja, debido a que los juegos están siempre en función del mejoramientos de estos 2 tipos de memoria, mediante figuras, tarjetas con animales, números, videos (animados), juguetes, historias, juegos de reproducción de posturas etc.

Aunque todas estas memorias se abordan de forma independiente desde la teoría, es válido destacar que durante la aplicación de la propuesta se debe trabajar de forma conjunta.

La propuesta de juegos recreativos se sustenta en los principales presupuestos que rigen la teoría de la actividad pedagógica y recreativa en Cuba, la cual rige el proceso enseñanza-aprendizaje tomando como imprescindibles, aquellos fundamentos como: el psicológico, el sociológico, el cognitivo, el pedagógico y el recreativo que se advienen concretamente a su concepción.

Para la elaboración del programa de juegos recreativos para educandos con discapacidad intelectual, se asumió la metodología de Pérez (2010), en la cual describe en 4 etapas los pasos lógicos para su confección.

Título: Jugando con la memoria

Objetivo general: contribuir a estimular la memoria en educando de 5to grado con discapacidad intelectual.

Coordinadores del programa: autores de la investigación

Vice-coordinadora del programa: directora

Responsable del programa: jefa de cátedra de Educación Física

\section{Juegos recreativos para estimular la memoria}

1. Nombre: recordando la postura. Objetivo: ejercitar la memoria. Medios: ninguno. Responsable: coordinadora del proyecto, directora y la profesora de Educación Física. Lugar: área del centro.

2. Nombre: igualito a. Objetivo: ajuntar objetivos y figuras que se relacionen. Medios: láminas con diferentes objetos, animales o figuras. Responsable: 
coordinadora del proyecto, directora y la profesora de Educación Física. Lugar: área del centro.

3. Nombre: cazadores del tesoro. Objetivo: recaudar la mayor cantidad de elementos. Medios: Objetos o juguetes (una lista de elementos que deben encontrar y otra con las pistas). Responsable: coordinadora del proyecto, directora y la profesora de Educación Física. Lugar: área del centro.

4. Nombre: cada cosa a su lugar. Objetivo: transportar objetos según su utilidad. Medios: mesa, cubiertos, pomos de champú, crema repisa, etc. Responsable: coordinadora del proyecto, directora y la profesora de Educación Física. Lugar: área del centro.

5. Nombre: viajeros al tren. Objetivo: ejercitar la memoria y atención. Medios: ninguno. Responsable: coordinadora del proyecto, directora y la profesora de Educación Física. Lugar: área del centro.

6. Nombre: descubriendo lo que falta. Objetivo: mejorar la atención. Medios: cartilla de dibujo. Responsable: coordinadora del proyecto, directora y la profesora de Educación Física. Lugar: área del centro.

7. Nombre: aprendo jugando. Objetivo: aumentar la capacidad de razonamiento. Medios: tarjetas con operaciones matemáticas, tarjetas enumeradas del 1 al 6, tiza, conos, aros. Responsable: coordinadora del proyecto, directora y la profesora de Educación Física. Lugar: área del centro.

8. Nombre: armemos la pirámide. Objetivo: retener la mayor cantidad de información posible. Medios: cubos de colores, objetos, conos, tizas, aros. Responsable: coordinadora del proyecto, directora y la profesora de Educación Física. Lugar: área del centro.

9. Nombre: las cosas que recuerdo. Objetivo: retener la mayor cantidad de información. Medios: objetos, figuras, laminas, aros, tizad, pelotas medianas y conos. Responsable: coordinadora del proyecto, directora y la profesora de Educación Física. Lugar: área del centro.

10. Nombre: observo y respondo. Objetivo: potencializar la atención, concentración y memoria. Medios: computadora o televisor, bocina y videos. Responsable: coordinadora del proyecto, directora y la profesora de Educación Física. Lugar: área del centro.

11. Nombre: descubre los animales escondidos. Objetivo: mejorar atención y memoria. Medios: imágenes donde hayan animales escondidos, lápices. Responsable: coordinadora del proyecto, directora y la profesora de Educación Física. Lugar: área del centro.

12. Nombre: corre el rumor. Objetivo: lograr que los niños retengan la mayor información del texto original. Medios: una noticia o texto escrito. Responsable: coordinadora del proyecto, directora y la profesora de Educación Física. Lugar: área del centro

13. Nombre: gánale al sudoku. Objetivo: potenciar la atención, concentración y memoria. Medios: Hojas, lápices, goma de borrar. Responsable: coordinadora del proyecto, directora y la profesora de Educación Física. Lugar: área del centro 
La aplicación del programa de juegos recreativos se efectuó en un período de 7 meses, comprendido noviembre y mayo, con un total de 34 frecuencias, desglosadas en 4 horas diarias para un total de 136 horas. Por otra parte, la propuesta fue revisada, aprobada y autorizada por la psicopedagoga y el consejo de dirección de la escuela. La aplicación de los juegos se llevó a cabo en las áreas deportivas y la sala polivalente de la escuela.

Durante la aplicación de los mismos, los educandos se mostraban alegres, ansiosos, emocionados, asombrados, estimulados, etc., la disciplina del grupo era buena y controlada, sin embargo aunque mostraron gran interés por los juegos, no se puede dejar de mencionar que existían problemas con la atención, con tendencia a la distracción con bastante facilidad, por lo investigadores insistían en mantener la motivación durante las actividades, herramienta que usaron para contrarrestar esta problemática. Los materiales para los juegos la mayoría fueron elaborados por los investigadores y otros pertenecían a la escuela.

\section{Tabla 2}

\begin{tabular}{lcccc}
\hline \multicolumn{1}{c}{ Test aplicadas } & \multicolumn{4}{c}{ Resultados } \\
\cline { 2 - 5 } & Alto & Medio & Bajo & Total \\
\hline Figuras incompletas & 12 & 4 & 2 & 18 \\
El rompecabezas & 18 & 0 & 0 & 18 \\
Memoria del ABC & 7 & 8 & 3 & 18 \\
Los objetos que recuerdo & 9 & 5 & 4 & 18 \\
\hline
\end{tabular}

Resultados de los test psicológicos aplicados en el post test

Para hacer el análisis comparativo de los test psicológicos se procedió con la técnica estadística de Wilcoxon:

Tabla 3

\begin{tabular}{lrrrr}
\hline & & ROMPECF - & MEMOF - & \multicolumn{2}{r}{ RECUERF - } \\
& FICHF - FICHI & ROMPECI & MEMOI & \multicolumn{1}{c}{ RECUEDI } \\
\hline$Z$ &,$- 707(\mathrm{a})$ & $-1,414(\mathrm{~b})$ & $-3,162(\mathrm{~b})$ & $-2,828(\mathrm{~b})$ \\
Sig. asintót. (bilateral) &, 480 &, 157 &, 002 &, 005 \\
\hline
\end{tabular}

Análisis comparativos de los test psicológicos

Se considera que el programa de juegos recreativos fue del agrado de los educandos, en cuanto a la memoria y los recuerdos existen cambios significativos mientras que en las fichas y el rompecabezas los resultados fueron pocos significativos según la dócima paramétrica de Wilcoxon. Es válido que aunque no todos los educandos alcanzaron resultados favorables, de forma general en la propuesta se perciben avances que permiten demostrar resultados positivos en cuanto a la propuesta de programa de juegos recreativos. Además se considera favorable extender la aplicación de la propuesta a un curso escolar para contribuir más con los resultados esperados.

La valoración realizada por los miembros del equipo multidisciplinario y directivos del centro con respecto a los resultados obtenido después de la aplicación de la propuesta fue de muy positiva, sugiriendo hacer extensiva la propuesta a todos los grupos de 5 to grado del centro, de igual forma dedicarle más tiempo, así como potenciar juegos que trabajen 
no solo la estimulación de la memoria sino que también estimulen y desarrollen otras áreas dentro de los procesos cognitivos.

\section{Conclusiones.}

- Se determinaron los fundamentos teóricos metodológicos que sustentan la importancia de los juegos recreativos para la memoria de educandos con discapacidad intelectual.

- El diagnóstico arrojó las principales problemáticas y características de los educandos, al mismo tiempo que se evidenció que no existe un programa de juegos recreativos en la escuela especial, confirmándose la necesidad de crear alternativas para darle solución al problema planteado en la investigación.

- El programa de juegos recreativos fue elaborado y aplicado según las necesidades y características de los educandos, lo que favorece la estimulación de la memoria y evidencia la viabilidad de la propuesta

- La implementación del programa de juegos recreativos, arrojó resultados favorables en cuanto a la estimulación de los procesos cognitivos, favoreciendo así a los educandos en función del trabajo correctivo y/o compensatorio.

\section{Referencias bibliográficas.}

Antonia, A. Tamayo, R. M., Licea, A. (2018). La memoria motriz y el programa educa a tu hijo. Revista Olimpia. Vol.15, Núm. 48 (2018): Edición especial. ISSN: 18179088. RNPS: 2067. Consultado el 27 de noviembre de 2019 en el sitio: olimpia@udg.co.cu

Armas, M. C. (2011), Propuesta de juegos terapéuticos para estimular la memoria en niños con retraso mental leve de la comunidad de Poey. Tesis en opción al Título Académico de Máster En Actividad Física en la Comunidad. La Habana, Cuba.

Barrios, et al. (2014). Propuesta psicopedagógica de estimulación psicomotriz para el desarrollo cognitivo de niños y niñas entre 5 y 13 años, que presentan retraso en el desarrollo psicomotor. Documento digital. Consultado el 3 de octubre de 2019 en el sitio: www.es.scridb.com

Bruner, N. (2007). La función del juego y su relación con el trabajo del duelo y la melancolía en la clínica psicoanalítica con bebe y niños con problema en el desarrollo. Tesis de maestría en psicoanálisis. Facultad de Psicología. Universidad de Buenos Aires

Bruner, N. (2016). La discapacidad, autismo y psicosis en la infancia?: elección, segregación e inclusión. VII Congreso Internacional de Investigación y Práctica Profesional en Psicología XXII Jornada de Investigación. XII Encuentro de investigadores de Psicología del MERCOSUR. Facultad de Psicología. Universidad de Buenos Aires. 
Capote, B. (2011). Actividades físico-deportivo para elevar la participación de los niños y las niñas con retraso mental a la recreación comunitaria del "Bello 26", municipio La Lisa. (Tesis de Maestría). Universidad de la Ciencia la Cultura Física y el Deporte "Manuel Fajardo". La Habana.

Castro, K. V. y Guayasamín F. O. (2011). Propuesta metodológica para la enseñanza de actividades físicas y recreativas en personas con déficit mental en el instituto piloto de integración del Azuay (IPIA)". Universidad de Cuenca. Ecuador.

Catalán, S. (2016). ¿Qué es la memoria? Recuperado desde: https://www.cipsiapsicólogos.com

Cifuentes, Forero y Urrego (2015). Fortaleciendo procesos de atención y memoria impactando el rendimiento académico en población con discapacidad cognitiva leve. Facultad de Ciencias Sociales y Humanas. Universidad Cooperativa de Colombia. Colombia.

Cobeñas, P. et al. (2017). Educación inclusiva y de calidad, un derecho de todos. Documento digital. Consultado el 30 de septiembre de 2019 en el sitio: www.grupoart24.org

Corona, F., Peñaloza, I. y Vargas, M. (2017). La inclusión de niños con discapacidad intelectual y en situación de calle: Una mirada comparativa entre Chile, Colombia y México. Revista Ensayos Pedagógicos Vol. XII, No 2 195-215, ISSN 16590104, Julio-diciembre, 2017. Consultado el 10 de octubre de 2019 en el sitio: http://dx.doi.org

Costa, M.; Romero, M.; Mallebrera, C.; Fabregat, E.; Martínez, MJ.; Martínez, Y. y Zaragoza; R. Torres, S.; Martínez, P. (2007). La importancia del diseño universal: Juego, juguetes y discapacidad. Alicante: Ed. AIJU.

Educación Especial e Inclusión Educativa (2016). Documento digital. Consultado el 30 de septiembre de 2019 en el sitio: www.unesco.org

Fernández, A.J. (2009). Programa de actividades recreativas para adolescentes con retardo mental moderado de 13 a 15 años de la comunidad Panamericano. Tesis de Maestría. Universidad de la Ciencia de la Cultura Física y el Deporte "Manuel Fajardo". Maracaibo. Venezuela.

Gavotto, N.H., Cañizares, H.M y Gavotto, N.O. (2015). La psicopedagogía en la actividad física (1ra ed.). México: Editorial Mexicana.

González, N. L. (2020) La recreación como estrategia pedagógica y medio de inclusión en personas con discapacidad cognitiva reflejado en calidad de vida. Tesis para optar al título de Especialista en Pedagogía. Universitaria Agustiniana, Facultad de Humanidades, Ciencias sociales y Educación. Bogotá, D.C. Colombia. 
Juegos recreativos para niños con Discapacidad Intelectual. Recuperado desde https://www.lifeder.com

Leyva, M. y Barreda, M. (2017). Precisiones para la atención educativa a escolares con necesidades educativas especiales asociadas o no a discapacidades. La Habana: Pueblo y Educación.

Pascual, A. (2008). Juegos adaptados. Una propuesta metodológica para la Educación Física de niños con necesidades educativas especiales por alteraciones motrices. Tesis de doctorado. Instituto Superior de Cultura Física "Manuel Fajardo". La Habana. Cuba.

Pérez, A. y Col. (2010), Recreación. Fundamentos teóricos y metodológicos, Empresa. Gráfica “Juan Marinello”. Cuba.

Plancarte, A. (2017). Inclusión educativa y cultura inclusiva. Revista Nacional e Internacional de Educación Inclusiva ISSN: 1889-4208.; e-ISSN 1989-4643. Volumen 10, Número 2, Diciembre 2017. Consultado el 26 de marzo de 2020 en el sitio: www.es.scribd.com

Revilla, L. (2016). Metodología para la estimulación de la motricidad en escolares con retraso mental moderado mediante juegos adaptados. Tesis de Doctorado. Universidad de la Ciencia la Cultura Física y el Deporte "Manuel Fajardo". La Habana. Cuba.

Rodríguez, F. J. (2010). Actividades físicas, deportivas y recreativas adaptadas, para incrementar la participación comunitaria de niñas y niños con retraso mental leve del municipio de Quemado de Güines en Villa Clara. (Tesis de Maestría). UCCFD "Manuel Fajardo". Villa Clara. Cuba.

Rubinsteins, S. (1971). Psicología del niño retrasado mental. La Habana: Editorial Pueblo y Educación.

Sánchez, N. et al. (2014). Concepción pedagógica de estimulación a potencialidades físicas en alumnos con retraso mental. Editorial Deportes. La Habana, Cuba.

Sánchez, R. y Sánchez, N. (2018). La Marcha de Orientación para escolares con retraso mental. Revista Acción, Vol. 14, ISSN 1608-3792, http://accion.uccfd.cu.

Watson Brown, H. (2008) Teoría y práctica de los juegos. Editorial Deportes. Ciudad de La Habana, Cuba.

Zambrano, A. y Vega, R. (2018). Conceptos de memoria. Recuperado desde https://www.hipocampo.org/memoria

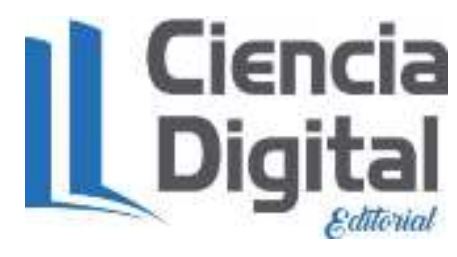




\section{PARA CITAR EL ARTÍCULO INDEXADO.}

Pérez López, D., Alvarez García, O., Sánchez Alberich, R., \& Velasteguí López, E. (2021). Los juegos recreativos como vía para la estimular la memoria en educandos con $\begin{array}{llll}\text { discapacidad intelectual. } & \text { Explorador } \quad \text { Digital, 5(4), }\end{array}$ https://doi.org/10.33262/exploradordigital.v5i4.1881

\section{Ciencia}

El artículo que se publica es de exclusiva responsabilidad de los autores y no necesariamente reflejan el pensamiento de la Revista Explorador Digital.

El artículo queda en propiedad de la revista y, por tanto, su publicación parcial y/o total en otro medio tiene que ser autorizado por el director de la Revista Explorador Digital.
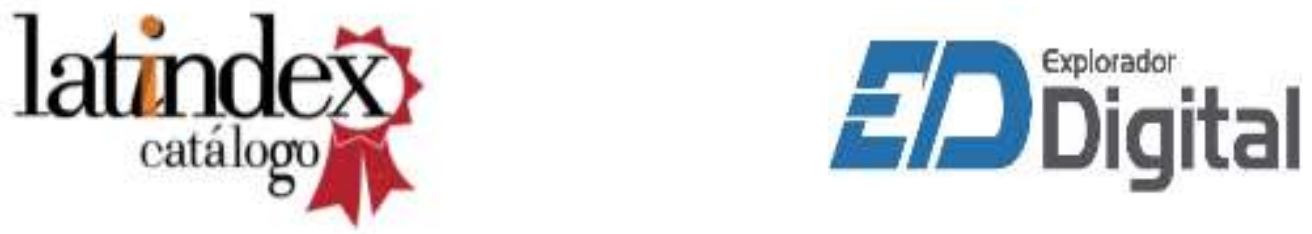